\title{
Increased expression of carbonic anhydrase I in the synovium of patients with ankylosing spondylitis
}

\author{
Xiaotian Chang ${ }^{1 *}$, Jinxiang Han ${ }^{1}$, Yan Zhao ${ }^{1}$, Xinfeng Yan², Shui Sun ${ }^{3}$, Yazhou Cui ${ }^{1}$
}

\begin{abstract}
Background: One of the most distinctive features of ankylosing spondylitis (AS) is new bone formation and bone resorption at sites of chronic inflammation. Previous studies have indicated that the hyperplasia and inflammation of synovial tissues are significantly related to the pathogenic process of AS. The present study used a proteomic approach to identify novel AS-specific proteins by simultaneously comparing the expression profiles of synovial membranes from patients with AS, rheumatoid arthritis (RA) and osteoarthritis (OA).

Methods: Synovial tissues were collected from the hip joints of patients with AS and knee joints of patients with RA or OA ( $n=10$ for each disease) during joint replacement surgery. Proteins extracted from the synovial tissues were separated by 2-D electrophoresis (2-DE), and the proteins with significantly increased expression in the AS samples were subjected to MALDI-TOF/TOF-MS analysis. The results were verified using western blotting and immunohistochemistry. Levels of the candidate proteins in synovial fluids from knee joints ( $n=40$ for each disease) were measured using ELISA.

Results: The proteomic approach revealed significantly increased expression of carbonic anhydrase I (CA1) in the synovial membrane of patients with AS as compared with the RA and OA tissue samples. Immunohistochemistry and western blotting analysis confirmed the findings described above. The ELISA detected a higher level of CA1 in synovial fluids from patients with AS than those with OA. The mean value of the CA1 level was also higher in AS patients as compared with RA patients. This study also detected increased expression of alpha-1-antitrypsin in the synovial tissues from AS patients, which is in agreement with other reports.

Conclusion: In vitro experiments by other groups indicated that $\mathrm{CA} 1$ catalyzes the generation of $\mathrm{HCO}_{3}{ }^{-}$through the hydration of $\mathrm{CO}_{2}$, which then combines with $\mathrm{Ca}^{2+}$ to form a $\mathrm{CaCO} 3$ precipitate. Calcification is an essential step of bone formation. Substantial evidence indicates that carbonic anhydrase also stimulates bone resorption. Hence, overexpression of CA1 in the synovial tissues of AS patients may promote improper calcification and bone resorption in AS.
\end{abstract}

\section{Background}

Ankylosing spondylitis (AS) is a chronic inflammatory disease that can cause significant complications by affecting the sacroiliac joints and axial skeleton. AS is characterized by two key pathologic features: sacroiliac joint and spinal inflammation and new bone formation

\footnotetext{
* Correspondence: changxt@126.com

${ }^{1}$ National Laboratory for Bio-Drugs of Ministry of Health, Provincial

Laboratory for Modern Medicine and Technology of Shandong, Research Center for Medicinal Biotechnology of Shandong Academy of Medical

Sciences. Jingshi road 18877, Jinan, Shandong, 250062, P. R. China

Full list of author information is available at the end of the article
}

with possible bone fusion, usually in the axial skeleton $[1,2]$. However, the pathologic mechanism of AS, especially the molecular mechanism of ossification, remains largely unclear. Histopathological experiments demonstrated that severe forms of AS significantly correlate with villous chronic synovitis, including obliterating vascularitis, fibrosclerosis, necrosis and calcification of disintegrated synovial structures [3]. The global disease activity of AS significantly correlates with hyperplasia of the synovial membrane as well as with inflammatory infiltration of macrophages, especially the CD163+ subset, and polymorphonuclear leukocytes [4]. These

\section{()


studies revealed that pathological changes in the synovium of patients with AS are closely related to disease progression.

Proteomics is a powerful new tool for rheumatology research. Using this approach, Liu et al. demonstrated high expression of the haptoglobin precursor in the sera of patients with AS [5]. Write et al. detected upregulation of the beta subunit of the proteasome activator PA28 in AS monocytes [6]. In the present study, we performed a proteomic analysis of AS synovial membranes and compared the expression profile with profiles from rheumatoid arthritis (RA) and osteoarthritis (OA) synovial membranes. AS has some similar symptoms to RA and was clinically classified as RA many years ago [7]. $\mathrm{OA}$ is arthritic disease involving the degradation of joints including articular cartilage and the adjacent subchondral bone. Therefore, comparing the expression profiles of these three diseases could effectively filter out inflammatory proteins and metabolism-related proteins to discover protein biomarkers that are specific to AS.

\section{Methods}

\section{Patients and sample collection}

Synovial tissues were collected during joint replacement surgery from patients with AS ( $\mathrm{n}=10,3$ female; 24-54 years old, mean 34$)$, RA ( $\mathrm{n}=10,8$ female; $30-65$ years old, mean 51) and OA ( $\mathrm{n}=10,4$ female; $40-72$ years old, mean 62). The AS tissues were collected from the hip joints of patients, and the RA and OA tissues were collected from the knee joints of patients. The samples were dissected from the connective tissues and immediately stored at $-80^{\circ} \mathrm{C}$ until use. AS patients had an average disease duration of 7 years and were positive for the HLA-B27 antigen. Their symptoms fulfilled the modified New York criteria for AS [8]. The diagnosis of RA fulfilled the American College of Rheumatology criteria. The patients with RA had disease durations of 3 to 10 years and were classified as having erosive RA (Larsen class IV-V). They had high levels of C-reactive protein (6-192 mg/liter, mean $70 \mathrm{mg} / \mathrm{liter}$ ), anti-CCP (92-394 U/ $\mathrm{ml}$ ) and RF (78-1280 U/ml). Patients with AS and RA took disease-modifying antirheumatic drugs (DMARDs) before surgery. Patients with AS, RA and OA were also medicated with non-steroidal anti-inflammatory drugs (NSAIDs), which help reduce the pain and swelling of the joints and decrease stiffness. Table 1 summarizes the epidemiological data.

Synovial fluids were aspirated from the joints of patients with AS ( $\mathrm{n}=40,12$ females; 26-54 years old, mean 35$)$, RA ( $\mathrm{n}=40,30$ females; $23-73$ years old, mean 44$)$ and OA ( $\mathrm{n}=40,16$ females; 47-86 years old, mean 61 ). Patients with AS had disease durations of 3 to 8 years. Patients with RA had disease durations of 3 to 10 years. Patients with OA had disease durations of 3 to 13 years. The diagnosis is described above. They were medicated with NSAIDs and DMARDs.

All patients provided informed consent, and the study protocol was approved by the Ethics Committee of the Shandong Academy of Medical Sciences.

\section{2-DE, protein spot collection and MALDI-TOF/TOF-MS analyses}

Synovial tissues were homogenized and added to lysis buffer (7 M Urea, 2 M thiourea, 4\% CHAPS, 2\% IPG buffer, $65 \mathrm{mM}$ DTT, $1 \mathrm{mM}$ PMSF and Protease Inhibitor Cocktail). The extracted proteins were purified with a 2-D Clean-Up Kit (GE Healthcare), which improves the quality of 2-D electrophoresis results by removing interfering contaminants. The concentrations of the protein samples were determined with the 2-D Quant Kit (GE Healthcare). Cell lysates from AS, RA and OA synovial tissues with equal protein content were pooled. Isoelectric focusing (IEF) was applied to 24-cm IPG strips (pH 3-10 NL; GE Healthcare) using an Ettan IPGphor II IEF system (GE Healthcare). One hundred microgram of the protein sample was applied on IPG strips. After equilibration, the second dimension was performed on $12.5 \%$ SDS-polyacrylamide gels at a consistent power supply (with initial separation at a constant $0.2 \mathrm{w} /$ gel for 1 hour followed by $17 \mathrm{w} /$ gel at $25^{\circ} \mathrm{C}$ ). The proteins were then stained with Coomassie Blue R350 (GE Healthcare) and scanned using a PowerLook $2100 \mathrm{XL}$ scanner system (Umax). Gel images were analyzed with the Imagemaster 5.0 software package (GE Healthcare), and the spots with a 3-fold intensity change were excised from the gels for MALDI-TOF/TOF-MS analysis.

Gel spot pieces were destained in $50 \mathrm{mM}$ ammonium bicarbonate $/ 50 \%$ acetonitrile $(\mathrm{ACN})$ buffer, dehydrated in $100 \% \mathrm{ACN}$ for 15 minutes, and then dried by vacuum centrifugation. The dried pieces were added to modified trypsin buffer (Promega) $(10 \mathrm{ng} / \mu \mathrm{l}$ in $25 \mathrm{mM}$ $\mathrm{NH}_{4} \mathrm{HCO}_{3}, \mathrm{pH} 8.0$ ) and incubated overnight at $37^{\circ} \mathrm{C}$. Peptides were extracted with $5 \%$ trifluoroacetic acid (TFA) $/ 50 \% \mathrm{ACN}(\mathrm{v} / \mathrm{v})$. After vacuum centrifugation, the lyophilized extract was redissolved in $0.1 \%$ TFA/ $30 \% \mathrm{ACN}(\mathrm{v} / \mathrm{v})$. Extracted peptides were mixed with an equal volume of $\alpha$-cyano-4-hydroxycinamic acid matrix ( $\alpha-\mathrm{CHCA})$ matrix (Sigma) and then spotted onto a standard 192-well plate for mass spectrometry analysis using an ABI 4700 Proteomics Analyzer MALDI-TOF/TOF mass spectrometer (ABI). Peptide mass fingerprinting (PMF) was acquired in a reflective mode, and at least two matched peaks were further validated by TOF-TOF analysis. The spectra data were searched against a human subset of the Swiss-Prot database for protein identifications using GPS explorer software. 
Table 1 Clinical data on patients with AS, RA and OA

\begin{tabular}{|c|c|c|c|c|c|c|c|c|c|c|c|}
\hline Diagnosis & Patient No. & Sex & $\begin{array}{c}\text { Age } \\
\text { (years) }\end{array}$ & HLA-B27 & $\mathrm{RF}$ & $\begin{array}{c}\text { anti-CCP } \\
\mathrm{U} / \mathrm{ml}\end{array}$ & $\begin{array}{c}\text { ESR } \\
(\mathrm{mm} \cdot \mathrm{h}-1)\end{array}$ & $\begin{array}{c}\text { CRP } \\
\text { (mg.dL-1) }\end{array}$ & $\begin{array}{c}\text { Disease duration } \\
\text { (years) }\end{array}$ & NSAIDs & DMARDs \\
\hline AS & 1 & male & 35 & + & - & - & 46 & 34 & 3 & yes & yes \\
\hline AS & 2 & male & 29 & + & - & - & 7 & 6 & 12 & yes & yes \\
\hline AS & 3 & male & 24 & + & - & - & 16 & 6 & 5 & yes & yes \\
\hline AS & 4 & male & 31 & + & - & - & 45 & 6 & 6 & yes & yes \\
\hline AS & 5 & male & 36 & + & - & - & 40 & 6 & 6 & yes & yes \\
\hline AS & 6 & male & 37 & + & - & - & 24 & 5 & 8 & yes & yes \\
\hline AS & 7 & male & 13 & + & - & - & 62 & 8 & 7 & yes & yes \\
\hline AS & 8 & female & 48 & + & - & - & 58 & 10 & 5 & yes & yes \\
\hline AS & 9 & female & 28 & + & - & - & 10 & 6 & 10 & yes & yes \\
\hline AS & 10 & female & 54 & + & - & - & 12 & 6 & 10 & yes & yes \\
\hline RA & 11 & female & 30 & ND & 100 & 209 & 80 & 6 & 4 & yes & yes \\
\hline RA & 12 & female & 58 & ND & 160 & 279 & 72 & 192 & 9 & yes & yes \\
\hline RA & 13 & female & 65 & ND & 496 & 218 & 66 & 153 & 7 & yes & yes \\
\hline RA & 14 & female & 41 & ND & 78 & 168 & 39 & 10 & 3 & yes & yes \\
\hline RA & 15 & female & 64 & ND & 200 & 169 & 61 & 10 & 5 & yes & yes \\
\hline RA & 16 & male & 53 & ND & 107 & 171 & 55 & 20 & 3 & yes & yes \\
\hline RA & 17 & female & 49 & ND & 160 & 227 & 50 & 96 & 4 & yes & yes \\
\hline RA & 18 & male & 50 & ND & 1280 & 394 & 84 & 153 & 6 & yes & yes \\
\hline RA & 19 & female & 53 & ND & 599 & 171 & 31 & 6 & 7 & yes & yes \\
\hline RA & 20 & female & 48 & ND & 107 & 92 & 13 & 60 & 10 & yes & yes \\
\hline $\mathrm{OA}$ & 21 & male & 40 & ND & - & ND & 10 & 6 & 6 & yes & - \\
\hline $\mathrm{OA}$ & 22 & female & 62 & ND & - & ND & 68 & 48 & 10 & yes & - \\
\hline $\mathrm{OA}$ & 23 & female & 53 & ND & - & ND & 20 & 6 & 8 & yes & - \\
\hline $\mathrm{OA}$ & 24 & female & 60 & ND & - & ND & 22 & 6 & 8 & yes & - \\
\hline $\mathrm{OA}$ & 25 & male & 66 & ND & - & ND & 24 & 10 & 6 & yes & - \\
\hline $\mathrm{OA}$ & 26 & female & 72 & ND & - & ND & 24 & 6 & 5 & yes & - \\
\hline $\mathrm{OA}$ & 27 & male & 65 & ND & - & ND & 5 & 10 & 11 & yes & - \\
\hline $\mathrm{OA}$ & 28 & male & 72 & ND & - & ND & 8 & 6 & 13 & yes & - \\
\hline $\mathrm{OA}$ & 29 & male & 68 & ND & - & ND & 24 & 6 & 7 & yes & - \\
\hline $\mathrm{OA}$ & 30 & male & 67 & ND & - & ND & 10 & 20 & 6 & yes & - \\
\hline
\end{tabular}

ND: no data available

\section{Western blot analysis}

Two hundred micrograms of each sample from synovial tissues ( $\mathrm{n}=5$ for each diseases) were homogenized in Cell Lysis Solution (Sigma) and centrifuged at 16,000 $\times$ $\mathrm{g}$ for $5 \mathrm{~min}$ at $4^{\circ} \mathrm{C}$. The supernatant was collected after centrifugation, and the protein concentration was determined using the BCA protein assay kit (Pierce). Five micrograms of total protein were loaded and separated by sodium dodecyl sulfate-polyacrylamide gel electrophoresis (SDS-PAGE), transferred onto nylon membranes and probed with anti-human carbonic anhydrase I (CA1) antibody (Abcam, USA). The antibody was prepared by immunizing a goat with carbonic anhydrase I extracted from human erythrocytes. The manufacturer confirmed no cross-reactivity with other carbonic anhydrases. Immunoreactive signals were detected with alkaline phosphatase-conjugated secondary antibodies and visualized using a western Blotting Luminol Reagent
(Amersham). Images of western blots were acquired on a Typhoon Trio (GE Healthcare). The quantification was conducted using ImageQuant5.2 software. Another membrane was prepared using the same protocol and probed with anti-GADPH antibody (Santa Cruz) to normalize for sample loading.

\section{Immunohistochemistry}

Synovial tissues ( $\mathrm{n}=10$ for each diseases) were fixed in $10 \%$ neutral buffered formalin for 12 hours at room temperature, embedded in paraffin and sectioned using standard procedures. Tissue sections were deparaffinized and rehydrated using standard procedures. To increase immunostaining intensity, the sections were heated at $95^{\circ} \mathrm{C}$ for $10 \mathrm{~min}$ in citrate buffer $(0.01 \mathrm{M}, \mathrm{pH} 6.0)$. Sections were incubated with the primary antibody overnight at $4^{\circ} \mathrm{C}$. Following incubation, tissue sections were washed three times for three minutes each in PBS and 
then processed with the UltraSensitive TM S-P kit (Maixin-Bio, China) according to the manufacturer's instructions. Immunoreactive signals were visualized using the DAB substrate, which stains the target protein a brown color. Tissue structure of the section was defined by counterstaining with hematoxylin.

\section{ELISA}

The fluid samples were centrifuged at $3,000 \times \mathrm{g}$ for 10 $\min$ at $4^{\circ} \mathrm{C}$ to remove debris. Fluid samples were diluted 20-fold with $0.05 \mathrm{M}$ carbonate-bicarbonate buffer ( $\mathrm{pH}$ 9.6) and were used to coat 96-well ELISA microplates (Costar) by overnight incubation at $4^{\circ} \mathrm{C}$. After a brief wash with PBS containing $0.1 \%$ Tween 20 (PBST), the plates were blocked with $5 \%$ non-fat dry milk for 1 hour at room temperature. The anti-CA1 antibody was diluted 1,000-fold with PBST, added to the plate, and incubated for 2 hours at room temperature. After washing with PBST, the plate was incubated with a 10,000fold dilution of anti-goat IgG alkaline phosphatase-conjugated antibody (Sigma) for $30 \mathrm{~min}$ at room temperature. Following a wash with PBST, the signal was developed by adding Alkaline Phosphatase Yellow (pNPP) Liquid Substrate System For ELISA (Sigma). The absorbance of the reaction was measured at 405 $\mathrm{nm}$ with a plate reader (Synergy HT, Bio-Tek).

Statistical analysis of the data was performed using SPSS V.16 software (SPSS, USA). Median differences were tested with the Mann-Whitney $U$ test. P values of less than 0.05 were considered significant. When three groups were compared, a Kruskal-Wallis test was conducted first.

\section{Results}

\section{Expression of CA1 in synovial membranes}

In the current study, comparative 2-DE was used to differentiate protein expression levels between the synovial membranes from AS and RA patients and AS and OA patients on a global scale. The experimental 2-DE gel patterns were highly reproducible over the three experiments. Following computational analysis, approximately 300 spots were visualized on each 2-DE gel. A 2-DE gel prepared with AS samples is shown in Figure 1. Two of the spots (\#5 and \#7) demonstrated 3 -fold higher expression in the AS sample as compared with the RA and OA controls (Figure 2). Using MALDI-TOF MS, the spots with increased expression in AS synovial tissues were identified as carbonic anhydrase I (CA1) and alpha-1-antitrypsin precursor (A1AT). The detailed information about these identified proteins is shown in Table 2. By comparing the expression profiles of AS synovial membranes with those of RA, five other protein spots were detected with more than 3-fold greater expression. These proteins were identified as serotransferrin precursor, hemopexin precursor, apolipoprotein A-I precursor, dedicator of cytokinesis protein 2 and intersectin 1. By comparing the expression profiles of AS synovial membranes with those of OA, 11 protein spots were detected with more than 3 -fold greater expression. These proteins were identified as Ig gamma1 chain $C$ region, dynein heavy chain, fibrinogen gamma chain precursor, catalase, $\mathrm{SH} 3$ and multiple ankyrin repeat domains protein 2, haptoglobin precursor, DNAdependent protein kinase catalytic subunit, apolipoprotein A-I precursor, serotransferrin precursor, microtubule-actin crosslinking factor 1 isoform 4 , and intersectin 1. However, these proteins were also expressed at increased levels in the synovial tissues of RA patients or in the synovial tissues of OA patients, and they were not specifically expressed at significantly increased levels in the synovial tissues of AS patients. Any differentially expressed spots demonstrating a less than 3-fold change were not addressed in the present study.

Western blot analysis was performed with antibodies against CA1. Using GADPH as a reference, CA1 showed significantly higher levels of expression in the synovial membranes of AS patients than in samples from RA and OA patients. The high level of expression was observed in all of five synovial membranes tested. Among the five OA synovial samples, only one sample had a relatively high CA1 expression. All of the RA synovial samples showed low levels of expression (Figure $3 \mathrm{~A}$ and $3 \mathrm{~B}$ ). A similar result was also obtained using $\beta$ actin as a reference.

Immunohistochemistry detected CA1 expression in all AS synovial tissues (100\%) and yielded high intensity signals. The CA1 immunosignal was observed in the lining layer, the endothelial cells around the small blood vessel and some fibroblast-like cells in the synovial membranes of AS patients. On the other hand, CA1 was detected in the thick lining layer of four samples of synovial membranes from RA patients (40\%), but the signal intensity was relatively low and appeared as a smear. CA1 was detected in six samples of synovial membranes from OA patients $(60 \%)$; the enzyme was detected in the upper lining within the thin layer of cells. The tissue distribution of CA1 is shown in Figure 4. The result is in agreement with the western blot analysis.

\section{Expression of CA1 in synovial fluid}

ELISA was used to measure the levels of CA1 in the synovial fluids from patients with AS, RA and OA at the chronic inflammation stage. CA1 levels were significantly elevated in AS fluids as compared with the OA samples $(p=0.032)$. Compared to the average level of the OA samples, fluid samples from AS patients had a 


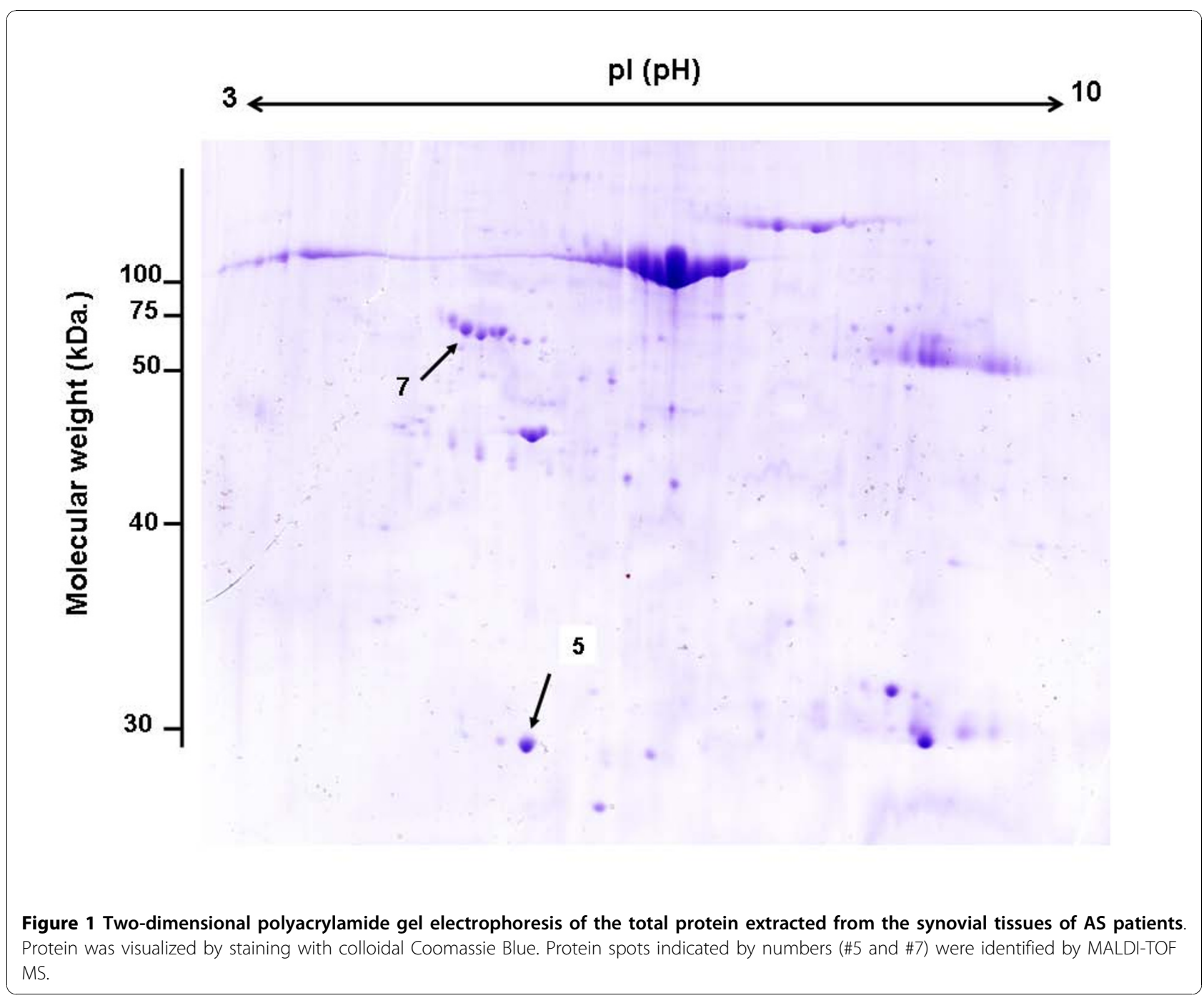

two-fold or greater increase in CA1 expression in 31 samples (77.5\%). Thirty-five of the AS samples (87.5\%) had relatively high levels of CA1 (O.D. > 2.0). This level did not significantly change among OA samples, and only two OA samples had higher levels of CA1 (O.D. > 2.0). Among the 40 RA synovial fluid samples, 12 samples had higher levels of CA1 (30\%, O.D. > 2.0). The mean levels of CA1 were higher in AS fluids than in RA fluids, although there was no statistically significant difference $(\mathrm{p}=0.056)$. The ELISA result is shown in Figure 5.

\section{Discussion}

In the present study, a proteomic approach exclusively identified the increased expression of CA1 in AS synovial membranes as compared with RA and OA samples. The increased expression of CA1 was confirmed by individually investigating synovial samples from each disease using western blot analysis. Immunohistochemistry also located CA1 in the AS synovial membranes with a strong signal density. Furthermore, the ELISA detected higher levels of CA1 in the synovial fluid from patients with AS compared to the OA samples. The mean value of the CA1 level is also higher in AS patients as compared to RA patients. The CA1 in the synovial fluid may be secreted by the AS synovial membranes.

Samples for each disease condition were pooled for 2-DE proteomics, which is regarded as the best practice in many studies to effectively find common features of diseased tissues under variable conditions. Under normal circumstances, proteomic research conducts a comparison of tissue samples from the two diseases, and it can consequently obtain many protein spots with specific expressions. In our study, we simultaneously compared the samples from three arthritic diseases, and we therefore obtained fewer but unique for the disease. Additionally, a significantly increased expression level of the alpha-1-antitrypsin (A1AT) precursor, which is an important plasma 


\section{\#5}

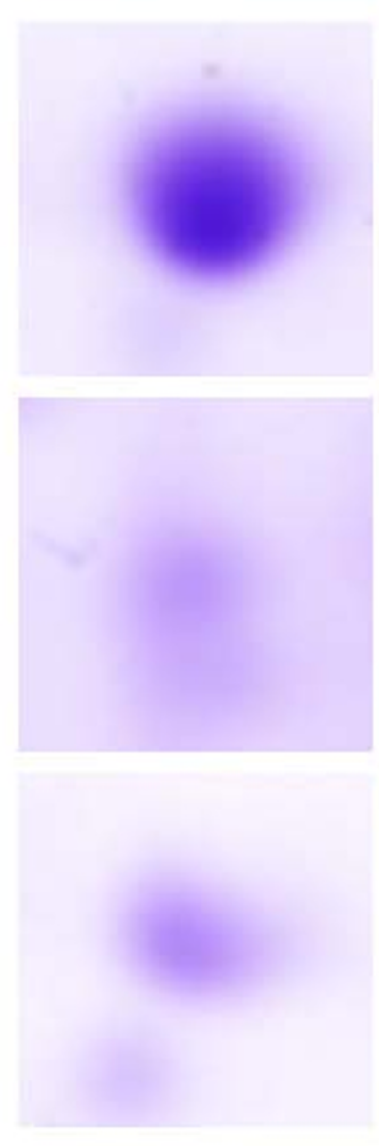

\#7

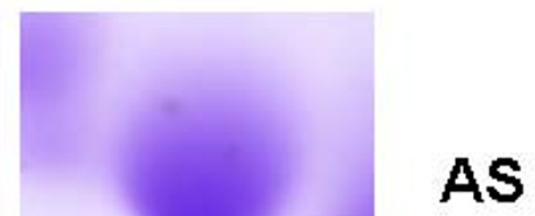

RA

\section{OA}

Figure 2 Comparison of the AS, RA and OA synovial proteins indicated by numbers in Figure 1. Protein spots (\#5 and \#7) from the AS synovial tissue had 3-fold higher expression levels than the matched spots from RA and OA synovium.

inhibitor of serine proteases, was detected in the synovial tissues of AS patients using a proteomic approach. Some reports have demonstrated the involvement of A1AT in the pathogenesis of AS. Increased levels of the complex of immunoglobulin with A-alpha 1 antitrypsin have been detected in the serum of AS patients and were associated with a clinical index of the disease $[9,10]$. Identifying A1AT in the synovial membrane of AS patients confirmed the feasibility and reliability of our protocol.

Tilleman et al. investigated the cytosolic proteome of inflamed synovial tissue and validated the feasibility of this proteomic analysis by identifying proteins that were

Table 2 Identification of spots with significant over-expression in AS synovial membrane by proteome analysis

\begin{tabular}{|c|c|c|c|c|c|c|c|}
\hline spot & protein name & $\begin{array}{l}\text { MW(kDa.) } \\
\text { theoretical }\end{array}$ & $\begin{array}{c}\text { pl } \\
\text { theoretical }\end{array}$ & $\begin{array}{l}\text { Peptide } \\
\text { count }\end{array}$ & $\begin{array}{l}\text { Protein } \\
\text { score }\end{array}$ & $\begin{array}{c}\text { Intensity matched } \\
\%\end{array}$ & $\begin{array}{c}\text { protein species score } C \text {. } \\
1 . \%\end{array}$ \\
\hline$\# 5$ & carbonic anhydrase 1 & 28778.4 & 6.63 & 9 & 135 & 80.75 & 100 \\
\hline \#7 & $\begin{array}{l}\text { alpha-1-antitrypsin } \\
\text { precursor }\end{array}$ & 46878.1 & 5.37 & 10 & 133 & 84.79 & 100 \\
\hline
\end{tabular}

MW, molecular weight; pl, isoelectric point. 

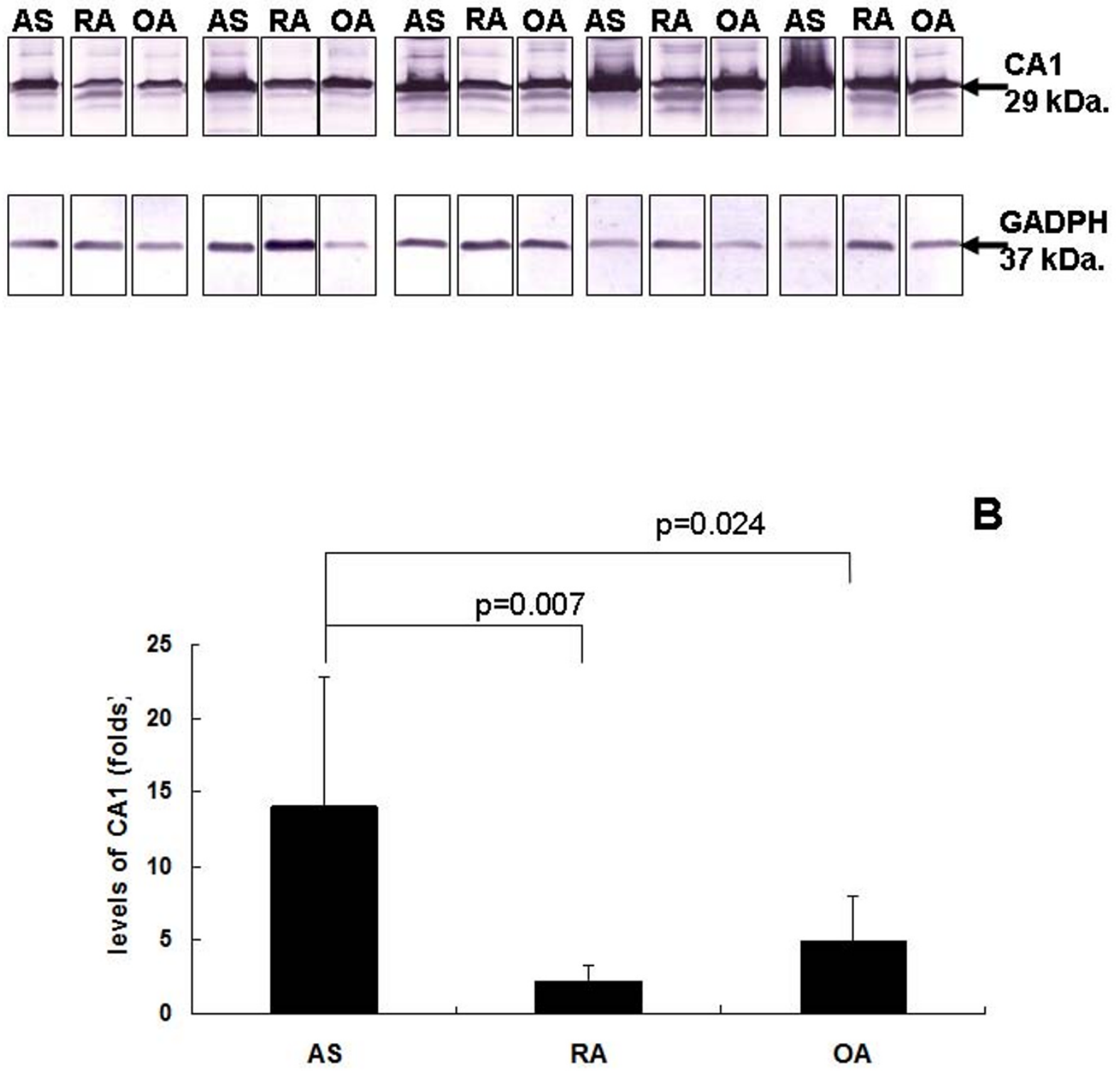

Figure 3 Western blot analysis of CA1 expression in synovial membranes from AS, RA and OA patients. (A) Western blotting of CA1 in $A S, R A$ and OA synovial tissues ( $n=5$ for each disease). The molecular weight is indicated with arrows. Sample loading was normalized using GADPH. (B) The CA1 signal was normalized to the GADPH signal. The expression levels are expressed as the mean \pm SEM. CA1 was expressed at a significantly higher level in AS synovial tissue than in RA and OA synovial tissues.

differentially expressed between AS, RA and OA. They collected synovial biopsy samples from 18 patients undergoing needle arthroscopy for knee synovitis associated with AS $(n=6)$ and RA $(n=6)$ and for joint effusion of the knee associated with $\mathrm{OA}(\mathrm{n}=6)$. Following 2-DE, protein expression patterns were statistically analyzed and used for hierarchical cluster analysis. Proteins of interest were identified by matrix-assisted laser desorption/ 


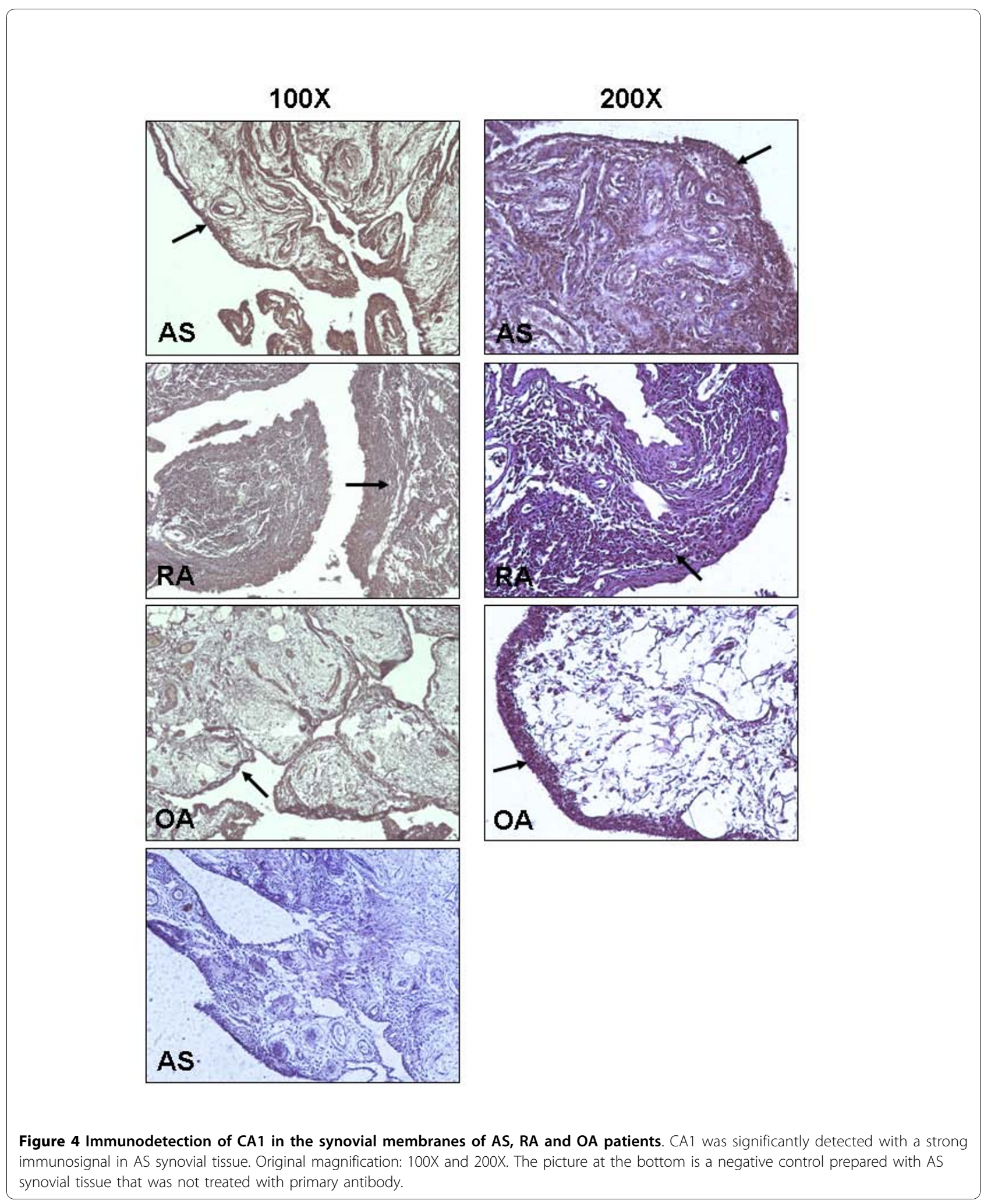




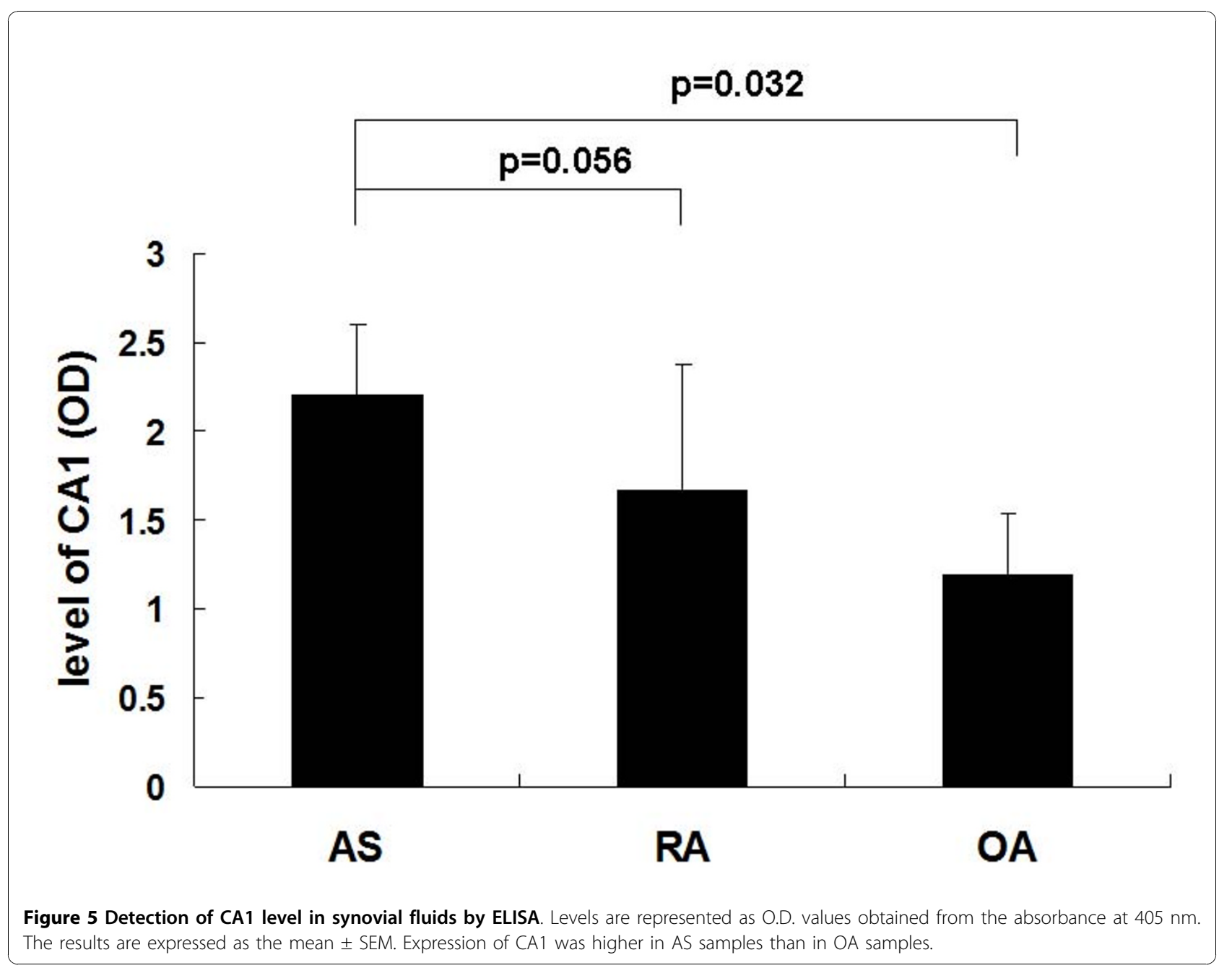

ionization- and electrospray ionization-mass spectrometry. By identifying proteins that were differentially expressed between AS and RA and AS and OA $(\mathrm{P}<0.01)$, they finally detected higher expression of fructose bisphosphate aldolase A and alpha-enolase in AS synovial tissues than in OA synovial tissues. They also detected a higher level of calgranulin A myeloid-related protein-8 in the RA and AS samples than in the OA samples [11]. In our study, we conducted a proteomic analysis with whole synovial membranes of hip joints from AS patients as opposed to synovial biopsy samples taken by needle arthroscopy from the knee joint of the patients. Additionally, we identified novel AS-specific proteins by simultaneously comparing the expression profiles of synovial membranes from patients with AS, RA and OA. We thus detected especially high expression of CA1 in the synovial tissues of AS patients. Because our patients and their patients all received treatment with NSAIDs and DMARDs before surgery, the medical treatment could not contribute to the differences in the findings of our study and their study.
CA1 catalyzes the hydration of carbon dioxide and forms bicarbonate [12]. Carbonic anhydrases (CA) participate in the physiological and pathological activities of calcification and mineralization [13]. Parissa et al. investigated the effect of CA1 on the hydration of $\mathrm{CO}_{2}$ and the formation of calcium carbonate. They conducted an in vitro assay using a reaction mixture containing bovine CA1 and calcium chloride in Tris buffer. After $\mathrm{CO}_{2}$ was added, CA1 enhanced the hydration reaction, and the hydration reaction rate increased with both the enzyme concentration and temperature. Furthermore, they found that CA1 promotes the formation of $\mathrm{CaCO}_{3}$ and the precipitant quickly settles [14]. Ramana et al. also detected $\mathrm{CaCO}_{3}$ deposition in a calcium chloride solution saturated with $\mathrm{CO}_{2}$ in the presence of carbonic anhydrase purified from Citrobacter freundii. They observed a sharp decrease in $\mathrm{CaCO}_{3}$ formation with the addition of EDTA and acetazolamide, inhibitors of carbonic anhydrase [15]. These results indicated that CA1 not only enhances the hydration reaction of $\mathrm{CO}_{2}$, but it 
also promotes the combining of bicarbonate with calcium to form the solid precipitant of calcium carbonate. Therefore, overexpression of CA1 in the synovium of AS patients may lead to $\mathrm{CaCO}_{3}$ deposition in diseased tissues. One of the most distinctive features of AS is new bone formation at sites of chronic inflammation [2]. Bone is mainly composed of calcium phosphate and calcium carbonate [16]. In the physiological milieu, a counterbalancing inhibition is required to prevent inappropriate formation of insoluble crystals of calcium salt $[17,18]$. Increased CA1 expression in the synovium of AS patients may lead to improper mineralization by accelerating calcium salt deposition.

Increased bone resorption is a characteristic of AS $[19,20]$. Using an in vitro neonatal mouse calvarial culture system, Hall et al. found that carbonic anhydrase activity enhanced the stimulation of prostaglandin $E_{2}$ for resorption, which indicates that carbonic anhydrase is a necessary component of the osteoclastic bone resorptive mechanism [21]. Two years later, the group found that the carbonic anhydrase inhibitor acetazolamide inhibited bone resorption [22]. Nolan et al. also found that carbonic anhydrase inhibitors including acetazolamide, ethoxzolamide, methazolamide, and dichlorphenamide reduced paw edema and attenuated joint deterioration in rats with adjuvant arthritis. They suggested that the carbonic anhydrase inhibitors played an antiarthritic role by inhibiting bone resorption [23]. These investigations demonstrated a functional role for carbonic anhydrase in the mediation of hormone-stimulated bone resorption [24]. Overexpression of CA1 in the synovium of AS patients may be involved in bone resorption of the disease. Additionally, studies have shown a high incidence of uveitis in patients with AS, and approximately $40 \%$ of patients with uveitis are also HLA-B27 positive $[25,26]$. Acetazolamide, inhibitor of CA1, is often used for the medical treatment of uveitis [27]. The high expression levels of CA1 in the synovial tissues of patients with AS may partially explain the strong association of the two diseases.

Most studies on AS focus on bone and bone development of the disease, although some studies had demonstrated that the global disease activity of AS significantly correlates with hyperplasia of the synovial membrane. Our results suggest that elevated expression of CA1 in the diseased synovial tissues plays a role in new bone formation and bone resorption. However, the importance of CA1 in AS processes is still unknown.

\section{Conclusions}

The current study detected increased expression of CA1 in the synovial tissue of AS patients. It has been demonstrated that $\mathrm{CA} 1$ can lead to $\mathrm{CaCO}_{3}$ precipitants.
Substantial evidence has indicated that carbonic anhydrase is also involved in bone resorption. These results suggest that the overexpression of CA1 in the synovium of AS patients may accelerate calcification and bone resorption, which are two essential processes for new bone formation. This finding may be helpful in understanding the pathogenic mechanism of AS.

\section{List of abbreviations}

AS: Ankylosing spondylitis; RA: rheumatoid arthritis; OA: osteoarthritis; 2-DE: 2-D electrophoresis; CA1: carbonic anhydrase I.

\section{Acknowledgements}

This study was supported by the National Natural Science Foundation of China (NTFC) (30671949, 30972720), the National Basic Research Program of China (2010CB529105), the Shandong Taishan Scholarship Progress, and Scientific and the Technological Project of Shandong Province (2009ZHZX1A1004).

\section{Author details}

${ }^{1}$ National Laboratory for Bio-Drugs of Ministry of Health, Provincial Laboratory for Modern Medicine and Technology of Shandong, Research Center for Medicinal Biotechnology of Shandong Academy of Medical Sciences. Jingshi road 18877, Jinan, Shandong, 250062, P. R. China. ${ }^{2}$ Orthopedic Surgery Center of Shandong Qianfoshan Hospital, Jinan, Shandong, P. R. China. ${ }^{3}$ Orthopedic Surgery Center of Provincial Hospital of Shandong, Jinan, Shandong, P. R. China.

\section{Authors' contributions}

$X C$ designed the study, executed data analysis and prepared the manuscript. $Y Z$ performed the immunohistochemistry, western blotting and ELISA. XY and SS recruited the patients and collected the synovial membranes and synovial fluids. $\mathrm{YC}$ and $\mathrm{JH}$ executed the proteomic study. All authors read and approved the final manuscript.

\section{Competing interests}

The authors declare that they have no competing interests.

Received: 6 May 2010 Accepted: 8 December 2010

Published: 8 December 2010

\section{References}

1. de Vlam K, Lories RJ, Luyten FP: Mechanisms of pathologic new bone formation. Curr Rheumatol Rep 2006, 8:332-337.

2. Zhang $X$, Aubin JE, Inman RD: Molecular and cellular biology of new bone formation: insights into the ankylosis of ankylosing spondylitis. Curr Opin Rheumatol 2003, 15:387-393.

3. Chen WS, Chen CH, Lin KC, Tsai CY, Liao HT, Wang HB, Chen YK, Yang AH, Chen TC, Chou CT: Immunohistological features of hip synovitis in ankylosing spondylitis with advanced hip involvement. Scand J Rheumatol 2009, 38:154-155.

4. Baeten D, Kruithof E, De Rycke L, Boots AM, Mielants H, Veys EM, De Keyser F: Infiltration of the synovial membrane with macrophage subsets and polymorphonuclear cells reflects global disease activity in spondyloarthropathy. Arthritis Res Ther 2005, 7:R359-369.

5. Liu J, Zhu P, Peng J, Li K, Du J, Gu J, Ou Y: Identification of diseaseassociated proteins by proteomic approach in ankylosing spondylitis. Biochem Biophys Res Commun 2007, 357:531-536.

6. Wright CA, Edelmann M, Digleria K, Kollnberger S, Kramer H, McGowan S, McHugh K, Taylor S, Kessler BM, Bowness P: Ankylosing spondylitis monocytes show upregulation of proteins involved in inflammation and the Ubiquitin Proteasome pathway. Ann Rheum Dis 2009, 68:1626-1632.

7. Helliwell PS: The semeiology of arthritis: discriminating between patients on the basis of their symptoms. Ann Rheum Dis 1995, 54:924-926. 
8. van der Linden S, Valkenburg HA, Cats A: Evaluation of diagnostic criteria for ankylosing spondylitis: a proposal for modification of the New York criteria. Arthritis Rheum 1984, 27:361-368.

9. Struthers GR, Lewin IV, Stanworth DR: IgA-alpha 1 antitrypsin complexes in ankylosing spondylitis. Ann Rheum Dis 1989, 48:30-44.

10. Davis MJ, Dawes PT, Beswick E, Lewin IV, Stanworth DR: Sulphasalazine therapy in ankylosing spondylitis: its effect on disease activity, immunoglobulin A and the complex immunoglobulin A-alpha-1antitrypsin. Br J Rheumatol 1989, 28:410-413.

11. Tilleman K, Van Beneden K, Dhondt A, Hoffman I, De Keyser F, Veys E, Elewaut D, Deforce D: Chronically inflamed synovium from spondyloarthropathy and rheumatoid arthritis investigated by protein expression profiling followed by tandem mass spectrometry. Proteomics 2005, 5:2247-2257.

12. Sterling D, Reithmeier RA, Casey JR: Carbonic anhydrase: in the driver's seat for bicarbonate transport. JOP 2001, 2:165-170.

13. Supuran CT: Carbonic anhydrases-an overview. Curr Pharm Des 2008, 14:603-614.

14. Parissa M, Koorosh A, Nader M: Investigating the Application of Enzyme Carbonic Anhydrase for $\mathrm{CO}_{2}$ sequestration purposes. Ind Eng Chem Res 2007, 46:921-926.

15. Ramanan R, Kannan K, Sivanesan SD, Mudliar S, Kaur S, Tripathi AK, Chakrabarti T: Bio-sequestration of carbon dioxide using carbonic anhydrase enzyme purified from Citrobacter freundii. World Journal of Microbiology and Biotechnology 2009, 25:981-987.

16. Boskey AL, Posner AS: Bone structure, composition, and mineralization. Orthop Clin North Am 1984, 15:597-612.

17. Anderson HC: Mechanism of mineral formation in bone. Lab Invest 1989, 60:320-330.

18. Provot S, Schipani E: Molecular mechanisms of endochondral bone development. Biochem Biophys Res Commun 2005, 328:658-665

19. Schett G: Bone formation versus bone resorption in ankylosing spondylitis. Adv Exp Med Biol 2009, 649:114-121.

20. Grisar J, Bernecker PM, Aringer M, Redlich K, Sedlak M, Wolozcszuk W, Spitzauer S, Grampp S, Kainberger F, Ebner W, Smolen JS, Pietschmann P: Ankylosing spondylitis, psoriatic arthritis, and reactive arthritis show increased bone resorption, but differ with regard to bone formation. J Rheumatol 2002, 29:1430-1436.

21. Hall GE, Kenny AD: Role of carbonic anhydrase in bone resorption induced by prostaglandin E2 in vitro. Pharmacology 1985, 30:339-347.

22. Hall GE, Kenny AD: Role of carbonic anhydrase in bone resorption: effect of acetazolamide on basal and parathyroid hormone-induced bone metabolism. Calcif Tissue Int 1987, 40:212-218.

23. Nolan JC, Gathright CE, Radvany CH, Barrett RJ, Sancilio LF: Carbonic anhydrase inhibitors are antiarthritic in the rat. Pharmacol Res 1991 , 24:377-383.

24. Pierce WM Jr, Waite LC: Bone-targeted carbonic anhydrase inhibitors: effect of a proinhibitor on bone resorption in vitro. Proc Soc Exp Biol Med 1987, 186:96-102.

25. Braun J, Sieper J: Early diagnosis of spondyloarthritis. Nat Clin Pract Rheumatol 2006, 2:536-545.

26. Chang JH, McCluskey PJ, Wakefield D: Acute anterior uveitis and HLA-B27. Surv Ophthalmol 2005, 50:364-388.

27. Cox SN, Hay E, Bird AC: Treatment of chronic macular edema with acetazolamide. Arch Ophthalmol 1988, 106:1190-1195.

\section{Pre-publication history}

The pre-publication history for this paper can be accessed here: http://www.biomedcentral.com/1471-2474/11/279/prepub

doi:10.1186/1471-2474-11-279

Cite this article as: Chang et al:. Increased expression of carbonic anhydrase I in the synovium of patients with ankylosing spondylitis. BMC Musculoskeletal Disorders 2010 11:279. 